\title{
SOSTENIBILIDAD E INCLUSIÓN SOCIAL (Sustainability and Social Inclusion)
}

Andrea García Donato

Grupo de Investigación -GIBS- Bogotá Sur

Corporación Universitaria Minuto de Dios UNIMINUTO

angarcia@uniminuto.edu

Resumen

Sostenibilidad e inclusión social son hoy discursos rimbombantes; su uso se ha masificado mientras su conceptualización es tan diversa que raya en la ambigüedad. Ambas condiciones deseables para la sociedad se originan en las consecuencias de la "insostenibilidad" del modelo de desarrollo económico dominante, sean estas la devastación del ambiente y la concentración de la riqueza en pocas manos, con lo que esto conlleva. En el marco de esta reflexión se plantea la relación del término sostenibilidad con el "desarrollo sostenible", cuya ambigüedad suscita la emergencia de propuestas críticas como la economía ecológica, que pretenden operativizar ese anhelo de cambiar la forma en que los seres humanos se relacionan con el ambiente. Estas como otras transformaciones necesarias en construcción de una sociedad incluyente, donde las instituciones de educación superior sean los espacios para la reflexión, la generación de conocimiento y la formación de profesionales en coherencia con estos propósitos.

Palabras clave: Sostenibilidad, Desarrollo sostenible, Inclusión social, Insostenibilidad.

Abstract

Today, sustainability and social inclusion are abundant and essential discourses; their use has become the norm WHILE their conceptualizations are so diverse and ambiguous. Both are socially desirable conditions rooted in "unsustainability" consequences of the dominant economic model; that is, the destruction of the environment and the concentration of wealth in very few hands. In this context, the relationship of the term sustainability with "sustainable development" generates critical proposals such as the emergence of an ecological economy which seek to operationalize the desire to change the way that human beings relate to the environment. These and other transformations are necessary to build an inclusive society where higher education institutions are spaces for reflection, knowledge generation and training of professionals in line with these purposes.

Key words: Sustainability, Sustainable development, Social inclusion, Unsustainability. 


\section{Del origen a las ambigüedades}

"La sostenibilidad sería asomarse a cualquier exterior $y$ ver que el paisaje sonríe, en lugar de llorar o huir despavorido hacia las catacumbas del horizonte".

Araujo (2002)

o sostenible actualmente se asume como un apellido para algunas acciones humanas susceptibles de ser cuestionadas por su impacto social y ambiental, poniéndolas a salvo de la crítica, por cuanto se considera que es lo se mantiene por sí mismo, sin comprometer los recursos de las generaciones futuras.

El término sostenibilidad viene ligado al término desarrollo sostenible, el cual aparece en el Informe sobre Nuestro futuro común (1987-1988) coordinado por Gro Harlem Brundtlandex, primera ministra de Noruega, en el marco de un requerimiento de las Naciones Unidas. El propósito de este informe fue brindar elementos para analizar, criticar y replantear las políticas de desarrollo económico globalizador, entendiendo el costo social y medio ambiental que está provocando la civilización industrial. Esto lleva implícita la idea de que el modelo de desarrollo económico imperante en la mayoría de países del mundo, a juzgar por el deterioro social y del ambiente que ha causado, sería "insostenible".

Desde allí se entiende el desarrollo sostenible como aquel que permite satisfacer nuestras necesidades actuales sin comprometer la capacidad de las generaciones futuras para satisfacer las suyas y busca reconciliar dos posturas opuestas; de un lado, estarían los desarrollistas, dedicados a las acciones necesarias para propiciar el crecimiento económico y, del otro, los críticos de esta postura preocupados por los impactos de este crecimiento económico en la sociedad $y$ en los ecosistemas.

Este discurso del desarrollo sostenible empieza a posicionarse y a convertirse en la bandera de grupos de activistas por la defensa del medio ambiente en particular, pues recoge un propósito que es deseable para muchos. No obstante, en la práctica se observan pocas acciones de cambio por parte de las multinacionales como potenciales productoras de las sustancias causantes de la degradación del medio ambiente y principales extractoras de los recursos naturales, con el consecuente impacto social. Al respecto menciona Araujo (2002): "Acordémonos de las declaraciones que Bush hizo en la Cumbre de Río 92. 'No ratificaremos nada que suponga el más mínimo cambio en el estilo de vida de los americanos"'. Es decir, que no se acepta rectificación alguna, cuando sabemos que es ese estilo de vida precisamente el principal responsable de la pobreza de la vida y de la mayoría. Para Naredo (20l0):

(...) Sin embargo, la falta de resultados inherente a la ambigüedad que exige el uso meramente retórico del término, se está prolongando demasiado, hasta el punto de minar el éxito político que acompañó a su aplicación inicial. La insatisfacción creciente entre técnicos y gestores que ha originado esta situación, está multiplicando últimamente las críticas a la mencionada ambigüedad conceptual y solicitando cada vez con más fuerza la búsqueda de precisiones que hagan operativo su uso". 
La señalada ambigüedad del término desarrollo sostenible ha dado paso a un uso indiscriminado del mismo, por lo cual se exige siempre precisar desde qué ámbito se habla de desarrollo sostenible. En ese sentido, autores como Trillo (2008) hablan de una concepción fuerte del desarrollo sostenible, que enmarca un discurso crítico sobre el desarrollo que se fundamenta en la condición de insostenibilidad generada por el modelo económico de desarrollo dominante.

\section{Las alternativas}

Estas reflexiones dejan clara la necesidad de modificar el modelo de desarrollo imperante, tomando como punto de partida un conocimiento profundo de la realidad y un diagnóstico certero sobre el estado, las causas y las consecuencias de la insostenibilidad. Esto es porque ante los numerosos estudios que han surgido para explicar la actual crisis ambiental, como una consecuencia de las prácticas del modelo económico de desarrollo, surgen igualmente informaciones que pretenden desmentirlos.

La mirada crítica de la ambigüedad del término desarrollo sostenible lleva a la implementación de propuestas para su operativización. Así, para Norton (1992), citado por Naredo (2010) habría “(...) Dos tipos de nociones de sostenibilidad diferentes que responden a dos paradigmas diferentes: una sostenibilidad débil (formulada desde la racionalidad propia de la economía estándar) y otra fuerte (formulada desde la racionalidad de esa economía de la física que es la termodinámica y de esa economía de la naturaleza que es la ecología)". Esta sostenibilidad fuerte centra su mirada en la salud de los ecosistemas, de los cuales los seres humanos y sus sistemas económicos forman parte; estaría dada en la posibilidad de abastecer de recursos el sistema económico y deshacerse de los residuos generados por estos procesos, lo cual implica cambios en los sistemas sociales que, cohesionados, deben asumir la organización y el mantenimiento de esta estructura, bajo la intención de la conservación del patrimonio natural.

En este orden de ideas, algunos autores reunidos en torno a la propuesta de la economía ecológica han procurado la determinación de unos criterios operativos del desarrollo sostenible, que serían el resultado de la integración de metodologías, enfoques y objetivos, entre economistas y ecólogos preocupados por el asunto de la sostenibilidad.

La economía ecológica pretende ser una respuesta teórica a un problema real, ampliando el marco teórico del desarrollo sostenible que se consideraba escaso. Critica el concepto de economía como un sistema cerrado, sin considerar entradas y salidas; bienes y servicios, familias, empresas, capital, tierra y trabajo como una estructura cíclica. Los materiales de la naturaleza, la energía solar y los desperdicios no tienen precio en el mercado y por eso estarían considerados fuera del sistema económico. La nueva apuesta vincularía la entrada de energía útil y materias primas a la vez que prescindiría de calor disipado y residuos materiales.

La economía ecológica identifica las principales causas humanas de la crisis ambiental en la depredación de la naturaleza a través de la utilización de recursos naturales a un ritmo no recuperable y lanzando contaminantes a un ritmo incapaz de ser reciclado por los ecosistemas. Asimismo, critica el supuesto de que materia y precio son equivalentes, ya que cuando se refiere a recursos no renovables, el equivalente en dinero no garantiza que se pueda obtener nuevamente el recurso como pasa con otros productos. 
Desde allí se entiende una dificultad inicial, que consiste en que el término desarrollo sostenible no ha tenido una conceptualización suficiente; que mantiene la comprensión del desarrollo de la economía tradicional, cuando este debería estar desligado del crecimiento económico tal y como se entiende, lo cual implica la ruptura entre el crecimiento y el desarrollo.

Otra ruptura que exige esta nueva mirada, es abolir el blindaje del discurso de la economía para dejarlo permear por el conocimiento de las bases físicas de la naturaleza; esto bajo una comprensión del sistema económico como un subsistema inserto en otro mayor, como es el ecológico o, si se quiere, la propia biosfera.

Esta visión exige reordenar los criterios bajo los cuales se toman las decisiones en la política económica y social, pues resulta inadecuado usar los instrumentos de la economía de mercado y centrar el objetivo en la eficiencia cuando se habla del uso humano de los recursos naturales. Si el interés es el bienestar humano, los criterios tendrían que ser principalmente éticos y no solamente económicos. Para Trillo (2008, p. 89):

La opción de prioridad en alcanzar objetivos mínimos de distribución, vinculada a la política que apuesta por la construcción de una sociedad humana sostenible, implica algo tan simple como supeditar la economía de mercado a la democracia política, en el doble sentido de conseguir la democratización de los poderes en todo el mundo, por un lado, y de evitar que las grandes corporaciones transnacionales se impongan sobre los sistemas de control de los gobiernos democráticos (algo que, sin embargo, viene ocurriendo de forma acelerada en el proceso de la llamada globalización económica), por otro.
La crisis ambiental y social global es una realidad que se hace evidente como suma de las problemáticas que hoy afectan los contextos locales. Es la expresión del exceso del subsistema económico sobre el sistema ecológico y sus efectos en la sociedad. Cambiar esta situación exige determinar unos criterios emanados de los múltiples estudios científicos que se han realizado alrededor del tema y unos acuerdos internacionales que garanticen el sustento y el bienestar para todos los seres del planeta.

\section{La inclusión social en el marco de la sostenibilidad}

La sostenibilidad como ética, equidad y racionalidad en el aprovechamiento del bienestar que provee la naturaleza, no puede estar dada en los mismos estándares de eficiencia del desarrollo económico, que resta interés a los medios cuando los fines consisten en dar más ganancias a quienes ya concentran la riqueza, perpetuando la desigualdad y la exclusión social.

Una verdadera voluntad estaría dada al mirar en profundidad las actividades que están causando la crisis, para luego integrar las ciencias de la naturaleza con la economía y así no quedarse en la mera retórica, sino que se trascienda a una reestructuración del sistema que priorice un uso eficiente de los recursos para generar menos perdidas en forma de residuos, bajo una mirada respetuosa y considerada sobre los ecosistemas y las demás especies que existen en ellos.

La inclusión social exige tener como sustrato una sociedad que abandone la idea de que la riqueza de la tierra le pertenece a un selecto grupo de familias, cuando debe la sociedad humana reconocerse como apenas 
una de los millones de especies que habitan el planeta y comparten el derecho de obtener su sustento de él.

La desigualdad y la pobreza, generadas por el sistema económico actual, se han convertido en el nicho para los altos índices de exclusión que se observan. En ese contexto, se ha entendido la escuela como el escenario llamado a ser el punto de partida para la superación de las desigualdades, en la construcción de una sociedad democrática, justa y equitativa.

A pesar de los avances en la formalización de estas apuestas a través de la política pública, la universalización de la educación primaria no se logra aún y la calidad y cobertura siguen estando limitadas para la población en condiciones más extremas.

Este ideal solo será el producto de la formación de la conciencia de que el desarrollo de la sociedad es posible desde un punto de vista más profundo, que implica entender la diferencia como riqueza y el respeto por el entorno natural como elementos de una postura ética frente a la vida. La inclusión social será difícil de alcanzar en el marco de insostenibilidad del que se habló anteriormente; para Cadenas:

(...) La actividad humana ya ha sobrepasado el estadio de una economía sin límites, sin fronteras, donde era relativamente factible solucionar los problemas de contaminación (...) en el contexto social, las implicaciones globales del funcionamiento del sistema capitalista son, asimismo, de sobra conocidas: Progresiva desigualdad social tanto entre espacios regionales como en el interior de los países, amenazas crecientes a la cohesión social así como a la calidad de vida incluso en los países más desarrollados, deterioro de la capacidad de acceso a servicios y bienes públicos tales como la seguridad, la educación y el cuidado de la salud, etc. (Cadenas 2002, p. 29)
Finalmente, sostenibilidad e inclusión social son condiciones deseables para toda la sociedad y lograrlas implica que se produzcan cambios sociales profundos que trasciendan las letras de acuerdos y normativas; que rompan con la lógica de la globalización de los mercados que, en aras del crecimiento económico, promueve la ruptura de las fronteras para la comercialización de la avalancha de productos cuya necesidad ha sido impuesta a través de los medios de comunicación, lo cual supone la homogeneización cultural, la exclusión social y la devastación del medio natural para dar abasto a la oferta y demanda de productos.

\section{La educación superior frente a la sostenibilidad e inclusión social}

El documento Lineamientos de política de educación superior inclusiva del Ministerio de educación Nacional en Colombia, define la educación inclusiva, según Carrillo (20l3), como una estrategia central para luchar contra la exclusión social. Esto es considerando una serie de condiciones que ponen a la persona en situación de rechazo, indiferencia o invisibilidad.

En ese orden de ideas, las instituciones de educación superior estarían llamadas a buscar las estrategias que permitan garantizar el derecho a la educación a todas las personas, generando las acciones pertinentes para que sus necesidades particulares puedan ser atendidas.

Igualmente, si la educación atiende la sociabilización del individuo, es en el marco de la misma que se deben dar las reflexiones y discusiones necesarias para la formación de individuos inclusivos; es decir, que la apuesta no se quede en cumplir la meta educati- 
va sino que se trascienda a la formación de individuos que entiendan la inclusión social como una postura frente a la vida y exijan a los gobiernos la suscripción de acuerdos y su cumplimiento en este propósito. Esto es, formación de individuos que en su desempeño como seres humanos y como profesionales tengan posturas éticas, equitativas, racionales y en coherencia con la búsqueda de una sostenibilidad que acoja a todas las personas sin distingos por condiciones físicas, sexuales, sociales, culturales o raciales, y que entienda la especie humana como una más dentro de la biosfera con derechos y deberes por ejercer, y que asumen la diversidad como una riqueza.

Igualmente, las instituciones de educación superior deberán incluir en sus agendas de investigación la sostenibilidad y la inclusión social, en la idea de generar las propias estrategias para aportar a la construcción de estas dos condiciones, para lo cual será conveniente extender la mirada a las experiencias positivas que se han dado en otros países sin perder de vista la propia identidad y la propia cultura.

Referencias bibliográficas

Aguado, J, (2002). Pensar en términos de sostenibilidad. Fundación Santander Central Hispano (ed.). Cuadernos de sostenibilidad y patrimonio natural. I, 26-27.

Araujo, J. (2002). Sociedad y desarrollo sostenible. Fundación Santander Central Hispano (ed.). Cuadernos de sostenibilidad y patrimonio natural. I, I28-I30.

Blanco, R, (2006). La equidad y la inclusión social: uno de los desafíos de la educación y la escuela hoy. Revista Electrónica lberoamericana sobre Calidad, Eficacia y Cambio en Educación -REICE. Vol. 4, No. 3.

Foladori, G. (200 I). La economía ecológica. En: Foladori, G. y Pierry, N. ¿Sustentabilidad? Desacuerdos sobre el desarrollo sustentable, pp. 189-196. Uruguay: Trabajo y Capital.

Naredo, J. (20I0). Sobre el origen, el uso y el contenido del término sostenible. Recuperado el 5 de septiembre de 20 I4, de Biblioteca virtual: Ciudades para un futuro más sostenible: http://habitat.aq.upm.es/cs/p2/a004.html

Trillo, J. (diciembre de 2008). La insostenibilidad como punto de partida del desarrollo sostenible. Revista iberoamericana de ciencia y tecnología. Vol. 4, N I I. Pag 89. Recuperado el I 8 de septiembre de 2014 de Scientific Electronic Library Online -SCIELO (Argentina): http://www.scielo.org.ar/scielo.php?script =sci_arttext\&pid $=$ SI $850-00$ I 32008000200006\&lng $=e s \& n r m=i s o$

Ministerio de Educación Nacional -MEN, Dirección de fomento para la educación superior. (20I3). Lineamientos de política de educción superior inclusiva (20I3). Bogotá D.C.: MEN. 